\title{
Frequency of clinically isolated strains of oral Candida species at Kagoshima University Hospital, Japan, and their susceptibility to antifungal drugs in 2006-2007 and 2012-2013
}

\author{
Yoshiaki Kamikawa ${ }^{1 *+}$, Youichirou Mori ${ }^{2 \dagger}$, Tomohiro Nagayama ${ }^{2}$, Junichi Fujisaki², Daisuke Hirabayashi²,
} Ryoichi Sakamoto ${ }^{2}$, Tomofumi Hamada² and Kazumasa Sugihara ${ }^{1,2}$

\begin{abstract}
Background: The isolation frequency and susceptibility to antifungal agents of oral Candida isolates from patients with oral candidiasis (OC) were compared between studies conducted in 2006-2007 and 2012-2013.

Methods: A total158 strains was isolated from 112 patients who visited Kagoshima University Hospital for the treatment of OC during the 14-month period from February 2012 and March 2013, and evaluated on the isolation frequency of each Candida strain and the susceptibility against antifungal drugs as compared to those evaluated in 2006-2007.

Results: There was a higher frequency of xerostomia as a chief complaint and of autoimmune disease in the 2012-2013 study than in the 2006-2007 study. More than 95\% of Candida isolates were C. albicans and C. glabrata. In addition, the proportion of the latter increased from $12.3 \%$ in the 2006-2007 study to $23.4 \%$ in the 2012-2013 study, while the proportion of the former decreased from $86.2 \%$ to $72.8 \%$, respectively. C. albicans was isolated in almost all patients, while C. glabrata was only isolated concomitantly with C. albicans. Minimal inhibitory concentrations (MICs) were not significantly different between groups with a few exceptions. Candida isolates, of which MICs surpassed break points, apparently increased for miconazole and itraconazole against C. glabrata in the 2012-2013 study, but this was not statistically significant. As a result, more cases of autoimmune disease, a greater number of $C$. glabrata isolates, and higher resistance to azoles were seen in the 2012-2013 study than in the 2006-2007 study.
\end{abstract}

Conclusion: These data indicate that with recent increases in C. glabrata infection, a causative fungus of OC, and in C. glabrata resistance to azoles, caution is needed in the selection of antifungal drugs for the treatment of OC.

Keywords: Candida glabrata, Candida albicans, Clinically isolated strains, Minimal inhibitory concentration, Resistant strains

\section{Background}

In the early 1990s, Candida albicans resistant to fluconazole was reported to be frequently isolated from the oral cavity of acquired immunodeficiency syndrome patients. An epidemiological study was conducted on the susceptibility to antifungal drugs of Candida strains isolated from patients with invasive candidiasis [1]. Global

\footnotetext{
* Correspondence: Kamikawa@dent.kagoshima-u.ac.jp

${ }^{\dagger}$ Equal contributors

1 Department of Oral Surgery, Kagoshima University Medical and Dental Hospital, 8-35-1 Sakuragaoka, Kagoshima 890-8544, Japan

Full list of author information is available at the end of the article
}

surveillance programs have been implemented for dealing with candidal resistance to antifungal drugs, such as the SENTRY program on fungi resistant to amphotericin B in 2006-2007 [2] and reports on candidal susceptibility to candin-type antifungals [3-6]. There are 2 reports on domestic surveillance in Japan: Surveillance 99 by the Japan Invasive Mycosis Surveillance Study Group (JMS) [7] and Report by Japan Antifungal Surveillance Program (JASP) [8-10]. However, these surveillance programs focused on strains isolated from clinical cases of deepseated mycosis, and only 1 report, our previous study 
performed in 2006-2007, was conducted on oral candidiasis [11].

The isolation frequency of Candida strains is likely to change over time, as shown by the comparisons of previous studies conducted in different time periods. For example, C. glabrata was rarely isolated from AIDS patients with oral candidiasis $(\mathrm{OC})$ or esophageal candidiasis in Sudo's study published in 1997 [12]; in contrast, C. glabrata was detected in $12.3 \%$ of patients with $\mathrm{OC}$ in our study, in which itraconazole (ITCZ) was effective despite the existence of resistant C. glabrata against ITCZ [11]. In addition, while resistant C. glabrata against ITCZ occurred with high frequencies of $50 \%$ and $72.7 \%$ in $\mathrm{OC}$ and non-OC patients of this study, respectively, [11], a previous Japanese surveillance study demonstrated resistant $C$. glabrata in only $1.0-9.3 \%$ of patients with mycosis, mainly deep-seated mycosis [7-10]. Thus, the isolation frequency of Candida species and their resistant strains varies over time, but no study has reported variations in frequency of $\mathrm{OC}$ over time in the same health facility.

The present study was undertaken to evaluate antifungal drugs against Candida strains isolated form the oral cavity of OC patients who visited Kagoshima University Hospital in 2012-2013 (14 months) and to assess the isolation frequency of Candida species and their resistant strains in comparison with our previous study conducted in 2006-2007 (24 months) in order investigate the use antifungal drugs in the treatment of OC.

\section{Methods}

\section{Subjects}

This study analyzed 158 strains isolated from 112 patients who visited the Department of Oral Surgery, Kagoshima University Hospital, for the treatment of OC during the 14-month period from February 2012 and March 2013. Strains collected from patients having received antifungal drug therapy within 3 months from collection were excluded from this study.

\section{Analysis of background variables of Candida-isolated patients}

An analysis was conducted for age, gender, underlying systemic disease, steroid hormone use, denture use, chief complaints, and oral disease in the 112 patients from whom Candida was isolated.

\section{Collection of Candida from the oral cavity and bacterial culture}

Prior to the diagnosis of $\mathrm{OC}$, the affected area of the oral cavity was wiped with a sterile cotton swab pre-immersed in sterile physiological saline. Fluid sample collected on the swab was smeared onto a CHROMagar Candida Culture Medium (Nippon Becton and Dickinson Company, Ltd.) and incubated for 48 hours at $36^{\circ} \mathrm{C}$.

\section{Identification of Candida species}

Positive culture of Candida species was determined by colorimetric observation of colonies in the CHROMagar Candida culture medium containing synthetic colorimetric substrates which are changed to be chromogenic by enzymes contained in Candida species. Confirmation of the determination of Candida species was then done by PCR based on the method reported from Kanbe et al., briefly fungal cells grown in the CHROMagar Candida culture medium were harvested by centrifugation, washed three times with distilled water, and the DNAs were extracted and purified according to the protocol of a DNA purification kit, Fast DNA Kit (BP Biomedical, U.S.). Then, the DNA samples were amplified by PCR and the PCR products were analyzed by agarose gel electrophoresis to determine the kind of Candida species [13].

\section{Diagnosis of OC}

Fluid collected on the swab from the affected area was transferred onto a glass slide for Gram staining by a routine method. A diagnosis of OC was made when colony formation was noted during incubation and the presence of pseudo mycelium was shown by Gram staining [14].

\section{Evaluation of susceptibility to antifungal drugs}

Candida strains detected by the above-mentioned methods were re-seeded onto Sabouraud agar medium (Nippon Becton and Dickinson Company, Ltd.), followed by 48 hour incubation at $36^{\circ} \mathrm{C}$. Then the culture was diluted and adjusted to a McFarland factor of 0.5 by measuring the optical density at $530 \mathrm{~nm}$ using a spectrophotometer ViSpec II (Kyokuto, Japan), and applied for the assay to determine the susceptibility. A minimum inhibitory concentration (MIC)of each of AMPH-B, 5-FC, FLCZ, MCZ, ITCZ, and MCFG against these Candida strains were determined with a Yeast-like Fungal Sensitivity Kit ASTY (Kyokuto Pharmaceutical) compatible with the National Committee for Clinical Laboratory Standards (NCCLS) M-27A method [15]. The kit includes 11 concentrations of each antifungal drug in a 96-well microplate, i.e. final concentrations $0,0.03,0.06,0.125,0.25,0.5,1,2,4,8$, and $16 \mu \mathrm{g} / \mathrm{mL}$ for amphotericin $\mathrm{B}$, miconazole, and micafungin, $0,0.125$, $0.25,0.5,1,2,4,8,16,32,64 \mu \mathrm{g} / \mathrm{mL}$ for fluconazole and 5FC, and $0,0.015,0.03,0.06,0.125,0.25,0.5,1,2,4$, and $8 \mu \mathrm{g} / \mathrm{mL}$ for itraconazole and micafungin. The concentration " $0 \mu \mathrm{g} / \mathrm{mL}$ " is regarded as a control. Strains with high MIC were subjected to re-measurement of MIC with a Yeast-like Fungal DP Eiken (Eiken Chemical) compatible with the Clinical and Laboratory Standards Institute (CLSI) M27-A3 method [10,16]. MIC50 and MIC90, MICs required to inhibit the growth of respective $50 \%$ and $90 \%$ of Candida species, were calculated. Resistant strains were determined by the following MIC criteria: AMPH-B, 
FLCZ, $\geq 64 \mu \mathrm{g} / \mathrm{mL} ; 5$-FC, $\geq 32 \mu \mathrm{g} / \mathrm{mL} ; \mathrm{MCZ}, \geq 4 \mu \mathrm{g} / \mathrm{mL}$; MCFG, $>2 \mu \mathrm{g} / \mathrm{mL}$; and ITCZ, $\geq 1 \mu \mathrm{g} / \mathrm{mL}$.

\section{Informed consent and ethical guideline}

All enrolled patients provided written informed consent upon directly providing verbal and written detailed explanation of this investigation. This study was approved by the Human Ethics Committee of the Kagoshima University Medical and Dental Hospital (No.23-18 and 23-27).

\section{Statistical analysis}

Fisher's exact probability test was employed to determine differences in gender $(2 \times 2)$, chief complaints $(2 \times$ $8)$, systemic disease (yes or no; $2 \times 2)$, steroid use $(2 \times 2)$, presence of dentures $(2 \times 2)$, oral candidiasis $(2 \times 4)$, composition of isolated Candida species $(2 \times 7)$, and the incidence of resistant strains between the 2006-2007 study and the 2012-2013 study. The difference in age between the 2 studies was examined by Student's $t$-test. $\mathrm{P}$ value less than 0.05 was regarded as statistically significant.

\section{Results}

\section{Background variables}

As shown in Table 1, there were no statistical differences in background variables in terms of gender, age, use of steroid hormone treatment, presence and the kind of systemic diseases and presence of dentures between patients in the 2006-2007 study and those of the 20122013 study. Among patients with 1 chief complaint, xerostomia was higher in the 2012-2013 study (23.2\%) than in the 2006-2007 study (8.8\%), while tylosis linguae was lower at $7.0 \%$ and $0 \%$, respectively. Collectively, the composition of chief complaints was significantly different between the 2006-2007 patients and 2012-2013 patients as analyzed by Fisher's exact probability test $(\mathrm{p}<$ 0.05). Despite no significant difference in the occurrence of systemic disease between the 2 studies $(77.2 \%$ vs. $86.6 \%)$, the presence of autoimmune diseases was higher in the 2012-2013 study than in the 2006-2007 study (27.6\% vs. $6.7 \%$, respectively).

\section{Classification of oral candidiasis (OC)}

Classification of diagnosed OC cases is also shown in Table 1. Among the 57 patients in the 2006-2007 study, OC was most frequently classified as pseudomembraneous OC (73.7\%), followed by erythematous OC (19.3\%). In the 2012-2013 study, however, erythematous OC accounted for half (46.4\%) of OC cases, followed by pseudomembranous OC (37.5\%) and mixed OC (erythematous and pseudomembranous, $12.5 \%$ ), but no statistical difference was noted.

\section{Isolated Candida species}

In total, 158 strains of Candida were isolated in patients in the 2012-2013 study. The most frequently isolated Candida species were Candida albicans (C. albicans, 116 strains, $73.4 \%$ ), followed by C. glabrata (36 strains, $22.8 \%$ ), C. tropicalis (3 strains, 1.9\%), C. parapsilosis (2 strains, $1.3 \%$ ), and C. krusei (1 strain, $0.6 \%$ ) (Table 2). When analyzed on a patient basis, C. albicans was isolated in all patients $(\mathrm{n}=112)$, while C. glabrata was never found on its own, only concomitantly with $C$. albicans in 36 patients. More than one kind of Candida species was isolated in 41 patients, with concomitant $C$. albicans and C. glabrata being the most common combination in approximately $90 \%$ of these patients. In contrast, among 65 strains of Candida isolated in patients in the 2006-2007 study, 56 strains of C. albicans (86.2\%), 8 strains of C. glabrata (12.3\%), and 1 strain of $C$. tropicalis (1.5\%) were identified, and no strains of $C$. parapsilosis and C. krusei were detected. Thus, in the 2012-2013 study, the number of isolated strains of $C$. glabrata was almost double that of the 2006-2007 study, and the ratio of $C$. albicans to all Candida strains was therefore significantly lower in the 2012-2013 study when analyzed on a strain-basis or on a patient-basis. Thus, in both patient-basis and strain-basis analyses, a statistical difference was observed between the 2006-2007 study and the 2012-2013 study ( $\mathrm{p}<0.01)$.

\section{Susceptibility to antifungal drugs}

Since few (1 to 3 strains) of the Candida species other than C. albicans and C. glabrata were isolated in either study, MIC values of antifungal drugs against $C$. tropicalis, C. parapsilosis, and C. krusei, which were never isolated alone but only in combination with $C$. albicans and $C$. glabrata, were not reliable. Therefore, the results of susceptibility testing mainly refer to the MICs of C. albicans and C. glabrata (Table 3).

\section{Amphotericin B (AMPH-B)}

The MIC was found to be low $(\leq 2 \mu \mathrm{g} / \mathrm{mL})$ in 63 (96.9\%) of the 65 strains in the 2006-2007 study and in 153 (99.4\%) of the 154 strains in the 2012-2013 study. Two strains of $C$. albicans in the 2006-2007 study and 1 strain of C. glabrata in the 2012-2013 study demonstrated high MIC of over $16 \mu \mathrm{g} / \mathrm{mL}$. However, the presence of resistant strains could not be detected in the concentration range used in this analysis. There was no obvious difference in the susceptibility of the 2 main Candida species, C. albicans and C. glabrata, between the 2 studies, with $\mathrm{MIC}_{90}$ values of $0.5 \mu \mathrm{g} / \mathrm{mL}$ and $2.0 \mu \mathrm{g} / \mathrm{mL}$, respectively, in the 2006-2007 study and of $1.0 \mu \mathrm{g} / \mathrm{mL}$ and $1.0 \mu \mathrm{g} / \mathrm{mL}$, respectively, in the $2012-$ 2013 study. 
Table 1 Background variables of patients with oral candidiasis enrolled in the 2006-2007 and 2012-2013 studies

\begin{tabular}{|c|c|c|c|c|c|c|}
\hline \multirow{4}{*}{$\begin{array}{l}\text { Subjects number } \\
\text { Gender }\end{array}$} & \multirow{3}{*}{$\begin{array}{l}\text { Total } \\
\text { Male }\end{array}$} & \multirow{2}{*}{\multicolumn{2}{|c|}{$\begin{array}{c}2006-2007 \\
57\end{array}$}} & \multirow{2}{*}{\multicolumn{2}{|c|}{$\frac{2012-2013}{112}$}} & \multirow{2}{*}{ Test } \\
\hline & & & & & & \\
\hline & & 19 & $(33.3)$ & 30 & $(26.8)$ & Fisher's exact probability test \\
\hline & Female & 38 & $(66.7)$ & 82 & $(73.2)$ & {$[2 \times 2]$} \\
\hline Age & Average [max-min] & 67.9 & {$[26-90]$} & 69.6 & {$[21-97]$} & Student's t-test \\
\hline \multirow[t]{9}{*}{ Chief Complaints } & Heat sensation(HS) & 23 & $(40.4)$ & 46 & $(41.1)$ & \\
\hline & Taste abnormality (TA) & 2 & (3.5) & 0 & $(0)$ & \\
\hline & Xerostomia $(X)$ & 5 & (8.8) & 26 & $(23.2)$ & \\
\hline & Tylosis linguae (TL) & 4 & $(7.0)$ & 0 & (0) & Fisher's exact probability test \\
\hline & Rubor/Erosion (R/E) & 4 & $(7.0)$ & 8 & $(7.1)$ & {$[2 \times 8]$} \\
\hline & $\mathrm{HS}+\mathrm{TA}+\mathrm{X}$ & 9 & $(15.8)$ & 16 & $(14.3)$ & $p<0.05$ \\
\hline & $\mathrm{HS}+\mathrm{TA}+\mathrm{R} / \mathrm{E}$ & 5 & $(8.8)$ & 8 & $(7.1)$ & \\
\hline & $\mathrm{HS}+\mathrm{TL}$ & 5 & $(8.8)$ & 8 & $(7.1)$ & \\
\hline & Total & 57 & $(100)$ & 112 & $(100)$ & \\
\hline \multirow[t]{11}{*}{ Systemic disease } & Yes & 44 & $(77.2)$ & 97 & $(86.6)$ & Fisher's exact probability test \\
\hline & None & 13 & $(28.8)$ & 15 & $(13.4)$ & {$[2 \times 2]$} \\
\hline & Total & 57 & $(100)$ & 112 & $(100)$ & N.S. \\
\hline & Endocrine & 22 & $(29.3)$ & 22 & $(17.3)$ & \\
\hline & Cardiovascular & 18 & $(24.0)$ & 28 & $(22.0)$ & \\
\hline & Gastrointestinal & 123 & $(16.0)$ & 12 & $(9.4)$ & Fisher's exact probability test \\
\hline & Malignant tumor & 8 & $(10.7)$ & 12 & (9.4) & {$[2 \times 7]$} \\
\hline & CNS & 4 & $(5.3)$ & 10 & $(7.9)$ & N.S. \\
\hline & Viral & 6 & $(8.0)$ & 8 & $(6.3)$ & \\
\hline & Autoimmune & 5 & $(6.7)$ & 35 & $(27.6)$ & \\
\hline & Total & 75 & $(100)$ & 127 & $(100)$ & \\
\hline \multirow[t]{3}{*}{ Steroid } & Dose & 12 & $(21.1)$ & 28 & $(25.0)$ & Fisher's exact probability test \\
\hline & Non-dosed & 45 & (78.9) & 84 & $(75.0)$ & {$[2 \times 2]$} \\
\hline & Total & 57 & $(100)$ & 112 & $(100)$ & N.S. \\
\hline \multirow[t]{3}{*}{ Denture } & Wearer & 37 & $(64.9)$ & 57 & $(50.9)$ & Fisher's exact probability test \\
\hline & Non-wearer & 20 & $(35.1)$ & 55 & $(49.1)$ & {$[2 \times 2]$} \\
\hline & Total & 75 & $(100)$ & 112 & $(100)$ & N.S. \\
\hline \multirow[t]{5}{*}{ Oral candidiasis } & Pseudomembranous & 42 & $(73.7)$ & 42 & $(37.5)$ & \\
\hline & Erythematous & 11 & $(19.3)$ & 52 & $(46.4)$ & Fisher's exact probability test \\
\hline & Hypertrophic & 2 & (3.5) & 4 & (3.6) & {$[2 \times 2]$} \\
\hline & Mixed & 2 & (3.5) & 14 & $(12.5)$ & N.S. \\
\hline & Total & 55 & (100) & 112 & (100) & \\
\hline
\end{tabular}

Figure in parentheses represents the percentage except the age.

\section{Flucytosine (5-FC)}

Two strains of C. albicans in the 2006-2007 study and 2 strains of C. albicans and 1 strain of C. glabrata in the 2012-2013 study demonstrated high MIC of more than $32 \mu \mathrm{g} / \mathrm{mL}$. There was no obvious difference in the susceptibility of C. albicans and C. glabrata between studies, with the 2006-2007 study demonstrating $\mathrm{MIC}_{90}$ of $0.5 \mu \mathrm{g} / \mathrm{mL}$ and $16 \mu \mathrm{g} / \mathrm{mL}$, respectively, and the 2012 2013 study, of $1.0 \mu \mathrm{g} / \mathrm{mL}$ and $8.0 \mu \mathrm{g} / \mathrm{mL}$, respectively.

\section{Fluconazole (FLCZ)}

MIC values were found below $64 \mu \mathrm{g} / \mathrm{mL}$ in 60 (92.3\%) of the 65 strains in the 2006-2007 study and in 146 (92.4\%) of the 158 strains in the 2012-2013 study. High MIC $\geq 64 \mu \mathrm{g} / \mathrm{mL}$ was recorded in 5 strains $(9.5 \%)$ in the 2006-2007 study, of which 3 strains were C. albicans, 1 strain was C. glabrata, and 1 strain was C. tropicalis, and in 12 strains (7.6\%) in the 2012-2013 study, of which 3 strains were C. albicans and 9 strains were 
Table 2 Distribution of Candida species isolated from patients with oral candidiasis in the 2006-2007 and 2012-2013 studies

\begin{tabular}{|c|c|c|c|c|c|}
\hline \multirow{2}{*}{ Candida species } & \multicolumn{4}{|c|}{ Number of patients (\%) } & \multirow{2}{*}{ Test } \\
\hline & \multicolumn{2}{|c|}{ 2006-2007 } & \multicolumn{2}{|c|}{$2012-2013$} & \\
\hline \multicolumn{6}{|l|}{ Single species isolated } \\
\hline Candida albicans (CA) & 49 & $(86.0)$ & 71 & $(63.4)$ & \\
\hline Candida glabrata (CG) & 1 & $(1.8)$ & 0 & (0) & \\
\hline Candida tropicalis (CT) & 0 & (0) & 0 & (0) & \\
\hline Candida parapsilosis (CP) & 0 & (0) & 0 & (0) & \\
\hline Candida krusei (CK) & 0 & (0) & 0 & (0) & Fisher's exact probability test \\
\hline Plural species isolated & & & & & {$[2 \times 10]$} \\
\hline$C A+C G$ & 6 & $(10.5)$ & 36 & $(32.1)$ & $p<0.01$ \\
\hline$C A+C T$ & 0 & (0) & 3 & $(2.7)$ & \\
\hline$C A+C P$ & 0 & (0) & 1 & $(0.9)$ & \\
\hline $\mathrm{CA}+\mathrm{CG}+\mathrm{CT}$ & 1 & $(1.8)$ & 0 & (0) & \\
\hline$C A+C P+C K$ & 0 & (0) & 1 & $(0.9)$ & \\
\hline Total & 57 & $(100)$ & 112 & $(100)$ & \\
\hline \multirow{2}{*}{ Candida species } & \multicolumn{4}{|c|}{ Total number of Candida strains isolated (\%) } & Toct \\
\hline & \multicolumn{2}{|c|}{ 2006-2007 } & \multicolumn{2}{|c|}{ 2012-2013 } & Test \\
\hline Candida albicans & 56 & $(86.2)$ & 112 & $(72.8)$ & \\
\hline Candida glabrata & 8 & $(12.3)$ & 36 & $(23.4)$ & \\
\hline Candida tropicalis & 1 & $(1.5)$ & 3 & $(1.9)$ & Fisher's exact probability test \\
\hline Candida parapsilosis & 0 & (0) & 2 & $(1.3)$ & {$[2 \times 5]$} \\
\hline Candida krusei & 0 & (0) & 1 & $(0.6)$ & $p<0.01$ \\
\hline Total & 65 & $(100)$ & 154 & $(100$ & \\
\hline
\end{tabular}

C. glabrata, and which were all found to be FLCZresistant strains. A higher proportion of resistant $C$. glabrata strains were found in the 2012-2013 study (9/36, 25.0\%) than in the 2006-2007 study $(1 / 8,12.5 \%)$. An increase in $\mathrm{MIC}_{50}$ of C. glabrata from $2 \mu \mathrm{g} / \mathrm{mL}$ in 2006-2007 to $16 \mu \mathrm{g} / \mathrm{mL}$ in 2012-2013 was also observed.

\section{Miconazole (MCZ)}

The MIC of 60 (92.3\%) of the 65 strains in the 20062007 study and in 139 (88.0\%) of the 158 strains in the 2012-2013 study were below $4 \mu \mathrm{g} / \mathrm{mL}$. High MIC $(\geq 4 \mu \mathrm{g} / \mathrm{mL})$ was recorded for 3 strains of C. albicans (4.6\%) and 2 strains of C. glabrata (25.0\%) in 20062007, and for 19 strains (12.0\%) in 2012-2013, of which 6 strains were $C$. albicans (5.4\%), 11 strains were $C$. glabrata (30.6\%), 1 strain was C. tropicalis (33.3\%), and 1 strain was C. krusei (100\%). Although $\mathrm{MIC}_{90}$ against C. glabrata in the 2012-2013 study $(16 \mu \mathrm{g} / \mathrm{mL})$ was higher than that in the 2006-2007 study $(4.0 \mu \mathrm{g} / \mathrm{mL})$, no other significant differences were seen between studies. The incidence of resistant C. glabrata was similar between the 2 studies at $25.0 \%$ (2/8 strains) and $30.6 \%$ (11/36 strains), respectively.

\section{Itraconazole (ITCZ)}

The MIC of 54 (83.1\%) of the 65 strains in the 20062007 study and of 127 (80.4\%) of the 158 strains in the 2012-2013 study were less than $1 \mu \mathrm{g} / \mathrm{mL}$. High MIC $(\geq 1 \mu \mathrm{g} / \mathrm{mL})$ was recorded in 11 strains $(16.9 \%)$ in $2006-$ 2007, of which 6 strains were C. albicans (10.7\%), 4 strains were C. glabrata (50.0\%), and 1 strain was C. tropicalis (100\%), and in 31 strains (19.6\%) in 2012-2013, of which 5 strains were C. albicans (4.5\%), 24 strains were C. glabrata (66.7\%), and 2 strains were C. tropicalis (66.7\%). There was a higher proportion of resistant strains of C. glabrata against ITCZ in the 2012-2013 study (24/36 strains, 66.7\%) than in the 2006-2007 study (4/8 strains, $50.0 \%$ ), but the difference was not statistically different. The $\mathrm{MIC}_{90}$ against $C$. glabrata was similar in both studies at $>8.0 \mu \mathrm{g} / \mathrm{mL}$, but that against $C$. albicans in the $2012-2013$ study $(0.25 \mu \mathrm{g} / \mathrm{mL})$ was lower than that in the 2006-2007 study $(1.0 \mu \mathrm{g} / \mathrm{mL})$.

\section{Micafungin (MCFG)}

The MIC of 63 (96.9\%) of the 65 strains in the 20062007 study and of 157 (99.4\%) of the 158 strains in the 2012-2013 study were $>4 \mu \mathrm{g} / \mathrm{mL}$. High MIC $(\geq 4 \mu \mathrm{g} / \mathrm{mL})$ was recorded in only 2 strains (4.6\%) in the 2006-2007 
Table 3 Antifungal susceptibility profile, against amphotericin B, flucytosine, fluconazole, miconazole, itraconazole, and micafungin, of Candida species isolated from patients with oral candidiasis in the 2006-2007 and 2012-2013 studies

\begin{tabular}{|c|c|c|c|c|c|c|c|c|c|c|c|c|c|c|c|c|}
\hline \multicolumn{17}{|c|}{ a. amphotericin B (AMPH-B) } \\
\hline \multirow{2}{*}{ Year } & \multirow{2}{*}{ Strain } & \multirow{2}{*}{$\begin{array}{l}\text { No. of } \\
\text { strains }\end{array}$} & \multicolumn{12}{|c|}{ MIC $(\mu \mathrm{g} / \mathrm{mL})$} & \multirow{2}{*}{$\mathrm{MIC}_{50}$} & \multirow{2}{*}{$\mathrm{MIC}_{90}$} \\
\hline & & & $<0.03$ & 0.03 & 0.06 & 0.125 & 0.25 & 0.5 & 1 & 2 & 4 & 8 & 16 & $>16$ & & \\
\hline \multirow[t]{3}{*}{ 2006-2007 } & C. albicans & 56 & & & & & 8 & 43 & 3 & & & & & 2 & 0.5 & 0.5 \\
\hline & C. glabrata & 8 & & & & 1 & 2 & 2 & 2 & 1 & & & & & 0.5 & 2 \\
\hline & C. tropicalis & 1 & & & & & 1 & & & & & & & & 0.25 & 0.25 \\
\hline \multirow[t]{5}{*}{ 2012-2013 } & C. albicans & 112 & & & & 4 & 12 & 86 & 9 & 1 & & & & & 0.5 & 1 \\
\hline & C. glabrata & 36 & & & & 1 & 2 & 16 & 14 & & 2 & & & 1 & 0.5 & 1 \\
\hline & C. tropicalis & 3 & & & & & & 1 & 2 & & & & & & 1 & 1 \\
\hline & C. parapsilosis & 2 & 2 & & & & & & & & & & & & $<0.03$ & $<0.03$ \\
\hline & C. krusei & 1 & & & & & & 1 & & & & & & & 0.5 & 0.5 \\
\hline \multicolumn{17}{|c|}{ b. flucytosine (5-FC) } \\
\hline \multirow{2}{*}{ Year } & \multirow{2}{*}{ Strain } & \multirow{2}{*}{$\begin{array}{l}\text { No. of } \\
\text { strains }\end{array}$} & \multicolumn{12}{|c|}{ MIC $(\mu \mathrm{g} / \mathrm{mL})$} & \multirow{2}{*}{$\mathrm{MIC}_{50}$} & \multirow{2}{*}{$\mathrm{MIC}_{90}$} \\
\hline & & & $<0.125$ & 0.125 & 0.25 & 0.5 & 1 & 2 & 4 & 8 & 16 & 32 & 64 & $>64$ & & \\
\hline \multirow[t]{3}{*}{ 2006-2007 } & C. albicans & 56 & 18 & 8 & 24 & 3 & 1 & & & & & & & 2 & 0.25 & 0.5 \\
\hline & C. glabrata & 8 & 4 & 1 & & 1 & & & & & 2 & & & & $<0.125$ & 16 \\
\hline & C. tropicalis & 1 & & 1 & & & & & & & & & & & 0.125 & 0.125 \\
\hline \multirow[t]{5}{*}{$2012-2013$} & C. albicans & 112 & 56 & 1 & 43 & 3 & 3 & 4 & & & & & 1 & 1 & 0.25 & 1 \\
\hline & C. glabrata & 36 & 20 & & & 6 & 6 & & & 2 & 1 & & 1 & & $<0.125$ & 8 \\
\hline & C. tropicalis & 3 & 3 & & & & & & & & & & & & $<0.125$ & $<0.125$ \\
\hline & C. parapsilosis & 2 & & & & & & & & & & & & & 2 & 2 \\
\hline & C. krusei & 1 & & & 1 & & & 1 & & & & & & & 0.25 & 0.25 \\
\hline \multicolumn{17}{|c|}{ c. fluconazole (FLCZ) } \\
\hline Year & Strain & No. of & & & & & MIC (1 & $/ \mathrm{mL})$ & & & & & & & MIC $_{5}$ & MIC \\
\hline Teai & Strain & & $<0.125$ & 0.125 & 0.25 & 0.5 & 1 & 2 & 4 & 8 & 16 & 32 & 64 & $>64$ & 50 & $1011-90$ \\
\hline 2006-2007 & C. albicans & 56 & & & 22 & 22 & 5 & 1 & 1 & 1 & & 1 & & 3 & 0.5 & 4 \\
\hline & C. glabrata & 8 & & & 1 & 2 & & 2 & 1 & & 1 & & & 1 & 2 & $>64$ \\
\hline & C. tropicalis & 1 & & & & & & & & & & & & 1 & $>64$ & $>64$ \\
\hline $2012-2013$ & C. albicans & 112 & 4 & & 33 & 51 & & 2 & 1 & 3 & 3 & & & 3 & 0.5 & 2 \\
\hline & C. glabrata & 36 & & & & & & 4 & 1 & 5 & 6 & 7 & 7 & 2 & 16 & 64 \\
\hline & C. tropicalis & 3 & & & & & & 1 & & & & 2 & & & 32 & 32 \\
\hline & C. parapsilosis & 2 & & & & & & 2 & & & & & & & 2 & 2 \\
\hline & C. krusei & 1 & & & & & & 1 & & & & & & & 2 & 2 \\
\hline d. miconaz & le (MCZ) & & & & & & & & & & & & & & & \\
\hline Year & Strain & No. of & & & & & MIC (1 & $/ \mathrm{mL})$ & & & & & & & MIC $_{5}$ & MIC \\
\hline Tear & Strain & & $<0.03$ & 0.03 & 0.06 & 0.125 & 0.25 & 0.5 & 1 & 2 & 4 & 8 & 16 & $>16$ & 50 & TII \\
\hline 2006-2007 & C. albicans & 56 & & 2 & 22 & 20 & 8 & 1 & & & & & & 3 & 0.125 & 0.25 \\
\hline & C. glabrata & 8 & & & 1 & & 2 & & 2 & 1 & 2 & & & & 1 & 4 \\
\hline & C. tropicalis & 1 & & & & & & & & & & & & & 0.125 & 0.125 \\
\hline 2012-2013 & C. albicans & 112 & & & 2 & 20 & 64 & 18 & 1 & 1 & 1 & 2 & & 3 & 0.25 & 0.5 \\
\hline & C. glabrata & 36 & & & & 1 & & 5 & 12 & 7 & 3 & 3 & 2 & 3 & 2 & 16 \\
\hline & C. tropicalis & 3 & & & & & & 1 & 1 & & 1 & & & & 1 & 4 \\
\hline & C. parapsilosis & 2 & & & & & & & 1 & 1 & & & & & $1-2$ & 2 \\
\hline & C. kurusei & 1 & & & & & & & & & 1 & & & & 4 & 4 \\
\hline
\end{tabular}


Table 3 Antifungal susceptibility profile, against amphotericin B, flucytosine, fluconazole, miconazole, itraconazole, and micafungin, of Candida species isolated from patients with oral candidiasis in the 2006-2007 and 2012-2013 studies (Continued)

\begin{tabular}{|c|c|c|c|c|c|c|c|c|c|c|c|c|c|c|c|c|}
\hline \multicolumn{17}{|c|}{ e. itraconazole (ITCZ) } \\
\hline \multirow{2}{*}{ Year } & \multirow{2}{*}{ Strain } & \multirow{2}{*}{$\begin{array}{l}\text { No. of } \\
\text { strains }\end{array}$} & \multicolumn{12}{|c|}{ MIC $(\mu \mathrm{g} / \mathrm{mL})$} & \multirow{2}{*}{$\mathrm{MIC}_{50}$} & \multirow{2}{*}{$\mathrm{MIC}_{90}$} \\
\hline & & & $<0.015$ & 0.015 & 0.03 & 0.06 & 0.125 & 0.25 & 0.5 & 1 & 2 & 4 & 8 & $>8$ & & \\
\hline \multirow[t]{3}{*}{ 2006-2007 } & C. albicans & 56 & & 4 & 20 & 14 & 9 & 2 & 1 & 3 & & 1 & & 2 & 0.06 & 1 \\
\hline & C. glabrata & 8 & & & 1 & & 1 & 1 & 1 & 1 & 1 & & & 2 & 0.05 & $>8$ \\
\hline & C. tropicalis & 1 & & & & & & & & & & & & & $>8$ & $>8$ \\
\hline \multirow[t]{5}{*}{$2012-2013$} & C. albicans & 112 & 2 & & 12 & 34 & 50 & 5 & 4 & 1 & 1 & & & 3 & 0.125 & 0.25 \\
\hline & C. glabrata & 36 & & & & 1 & 3 & 3 & 5 & 9 & 8 & 2 & & 5 & 1 & $>8$ \\
\hline & C. tropicalis & 3 & & & & & & & 1 & 1 & 1 & & & & 1 & 2 \\
\hline & C. parapsilosis & 2 & & & & & 1 & 1 & & & & & & & 0.25 & 0.25 \\
\hline & C. kurusei & 1 & & & & & & & 1 & & & & & & 0.5 & 0.5 \\
\hline \multicolumn{17}{|c|}{ f. micafungin (MCFG) } \\
\hline \multirow{2}{*}{ Year } & \multirow{2}{*}{ Strain } & \multirow{2}{*}{$\begin{array}{c}\text { No.of } \\
\text { strains }\end{array}$} & \multicolumn{12}{|c|}{ MIC $(\mu \mathrm{g} / \mathrm{mL})$} & \multirow{2}{*}{$\mathrm{MIC}_{50}$} & \multirow{2}{*}{$\mathrm{MIC}_{90}$} \\
\hline & & & $<0.03$ & 0.03 & 0.06 & 0.125 & 0.25 & 0.5 & 1 & 2 & 4 & 8 & 16 & $>16$ & & \\
\hline \multirow[t]{3}{*}{ 2006-2007 } & C. albicans & 56 & 32 & 9 & 13 & & & & & 1 & & & & 1 & $<0.03$ & 0.06 \\
\hline & C. glabrata & 8 & 1 & & 2 & 2 & 1 & 1 & & & & & & 1 & 0.125 & $>16$ \\
\hline & C. tropicalis & 1 & & & 1 & & & & & & & & & & 0.06 & 0.06 \\
\hline \multirow[t]{5}{*}{$2012-2013$} & C. albicans & 112 & 95 & & 12 & 2 & 1 & 1 & 1 & & & & & & $<0.03$ & 0.06 \\
\hline & C. glabrata & 36 & 16 & 1 & 1 & 3 & 5 & 6 & 1 & 2 & 1 & & & & 0.125 & 1 \\
\hline & C. tropicalis & 3 & 2 & & 1 & & & & & & & & & & $<0.03$ & 00.6 \\
\hline & C. parapsilosis & 2 & 2 & & & & & & & & & & & & $<0.03$ & $<0.03$ \\
\hline & C. kurusei & 1 & & & & & & & & & & & & & 0.5 & 0.5 \\
\hline
\end{tabular}

study, of which 1 strain each was C. albicans and C. glabrata, and 1 strain of C. glabrata in the 2012-2013 study. Although the $\mathrm{MIC}_{90}$ against C. glabrata in 2012-2013 $(1.0 \mu \mathrm{g} / \mathrm{mL})$ was lower than in $2006-2007(>16 \mu \mathrm{g} / \mathrm{mL})$, there was no other obvious differences in the susceptibility of C. albicans and C. glabrata between studies.

\section{Discussion}

Non-C. albicans Candida (NCAC) strains have been isolated in increasing numbers in medically compromised patients including those with $\mathrm{OC}$ and denture stomatitis. C. albicans remains the most common fungus associated with infection, followed by C. glabrata. In clinically isolated samples from the blood, urine, and tracheal secretion of candidemia patients, the isolation frequency of $C$. glabrata has been found to be $16-26 \%$, which is the highest among NCAC strains [17-20]. In the Prospective Antifungal Therapy Alliance (PATH Alliance ${ }^{\circ}$ ), in which 3,648 patients with candidemia were enrolled from 2004 to 2008 in the US, the most common Candida species was C. albicans (42.1\%), followed by C. glabrata (26.7\%), and the proportion of candidemia caused by NCAC strains was higher than that caused by C. albicans [21]. Such a high emergence of NCAC strains, especially of $C$. glabrata, in candidemia has recently been reported, with a higher incidence of C. glabrata found from 2006 to 2010 (range: $4.8-23.5 \%, \mathrm{P}=0.024$ ) in Brazil [22]. In addition, the prevalence of infection due to a specific Candida species may vary by geographic region [23].

However, few reports exist on differences in variation of isolation frequency and its relation to candidemia in oral candidiasis. In contrast, there are several reports on oropharyngeal Candida infections due to C. glabrata $[24,25]$. In the present study, the isolation frequency of C. glabrata increased from $14.1 \%$ in $2006-2007$ to $32.1 \%$ in 2012-2013 when assessed by the number of patients, indicating a similar tendency observed in Japanese OC patients. The tendency of a shift of NCAC species would also be attributable to frequent and wide use of azole antifungal drugs, such as fluconazole, in the treatment of mycosis [26]. Moreover, the isolation frequency of NCAC strains, especially C. glabrata, was reported to increase [26-28]. In Japan, as a result of a wide use of azole antifungal drugs as the standard remedy for deep-seated mycosis, it is supposed that the isolation frequency of C. glabrata became high.

By comparing background data of OC patients in the 2012-2013 study and in the 2006-2007 study, the 
following differences were observed: (1) the frequency of xerostomia as a chief complaint increased from $24.6 \%$ to $37.5 \%$ of patients, (2) autoimmune disorders as a systemic disease increased from $6.7 \%$ to $27.6 \%$, and (3) erythematous OC as a type of OC increased from $19.3 \%$ to $46.4 \%$. Differences in the frequency of xerostomia and autoimmune disorders were associated with an increase in patients with Sjögren's syndrome, a chronic and progressive autoimmune disorder mainly characterized by xerostomia. Differences in erythematous OC may be partly attributed to an increase in simultaneous identification of $C$. albicans and C. glabrata as observed in $32.1 \%$ of patients in the 2012-2013 study. In fact, cases of mixed infection suggest that $C$. albicans enhances the invasiveness of C. glabrata, and leads to increased lactate dehydrogenase (LDH) release from a reconstituted human oral epithelium (RHOE) in vitro [29]. Furthermore, LDH release paralleled the observed histological damages in RHOE, which may be associated to the increase in erythematous OC.

By comparing the susceptibilities of patients in the 2012-2013 study with that of the 2006-2007 study, azole antifungal drugs (FLCZ, MCZ, and ITCZ) demonstrated high $\mathrm{MIC}_{90}$ values against C. glabrata in both studies. In particular, the $\mathrm{MIC}_{90}$ value of MCZ against C. glabrata increased from $4 \mu \mathrm{g} / \mathrm{mL}(2006-2007)$ to $16 \mu \mathrm{g} / \mathrm{mL}(2012-$ 2013). Such high MIC values of azole antifungal drugs, which suggest a decrease in the susceptibility of C. glabrata to these drugs, have been recognized in several studies [17-19,30]. Decreased susceptibility to FLCZ was mainly seen against C. glabrata isolated from patients with blood stream infections, with a dose-dependent susceptibility rate of $76.5 \%$, while the susceptibility rates of FLCZ were $100 \%$ for C. albicans and C. parapsilosis [19]. Similar results were also found for systemic candidiasis [18,20,23]. Decreases in the susceptibility of NCAC, especially of $C$. glabrata, resulted from resistance to FLCZ, leading to oropharyngeal Candida infections, which are more severe and more difficult to treat in HIV-infected and cancer patients [30]. The development of resistance in C. glabrata was observed against other azoles, such as ITCZ and ketoconazole [20,31]. In addition, in the present study, although statistical significance was not obtained, resistant strains of C. glabrata increased from $50.0 \%$ (4/8) in the 2006-2007 study to $66.7 \%(24 / 36)$ in the 2012-2013 study. In cases of other azole antifungal drugs, FLCZ and MCZ, resistant strains of C. glabrata increased slightly from $12.5 \%$ to $25.0 \%$ and from $25.0 \%$ to $30.6 \%$, respectively. Thus, a tendency for increased isolation frequencies of resistant $C$. glabrata against azole antifungal drugs, especially ITCZ have been observed. Frequent exposure of antifungal drugs, especially azoles, is known to lead to an increase in resistant Candida strains, which has been reported since fluconazole was clinically available in 1989.
After that new azole antifungal drugs, such as itraconazole and voliconazole, have been widely used for deep-seated mycosis. Thus, increases in clinically available antifungal azole drugs and in their clinical usages for the treatment of deep-seated mycosis could lead to an increment of resistant Candida strains. This tendency would be still continuing during the period of 2006-2013.

\section{Conclusions}

In oral Candida species isolated from OC patients, the ratio of C. glabrata to C. albicans increased in the 20122013 study as compared to the 2006-2007 study, accompanying the tendency of increases in tolerant strains of $C$. glabrata against azole antifungal drugs and in cases of autoimmune disease. The higher isolation frequency of $C$. glabrata, especially of co-isolation frequency with C. albicans, may be associated with the increase in erythematous OC. Considering the increase in C. glabrata resistant strains against azoles, selection of appropriate antifungal drugs and dosing regimens against resistant C. glabrata, as well as against $C$. albicans is important.

\section{Competing interests}

The authors declare that they have no competing interests.

\section{Author's contribution}

KY and MY participated in the design of the study, conducted the study, and conducted the data collection and analyses, and drafted the manuscript. NT, FJ, HD, SR, HT, and SK, participated in the design of the study and carried out the data collection. All authors contributed to the writing of the manuscript and critically reviewed the final version. All authors read and approved the final manuscript.

\section{Acknowledgments}

We express special thanks to Akihiro Mastuura, Ph.D., Medi-Phi Co. Ltd., for providing a great help for statistics of data.

\section{Funding support}

This study was supported by Grants-in-Aid 19390521 (Sugihara K.), 22592217 (Kamikawa Y.), from the Ministry of Education, Culture, Sports, Science and Technology of Japan and by the JSPS Fellowship.

\section{Author details}

'Department of Oral Surgery, Kagoshima University Medical and Dental Hospital, 8-35-1 Sakuragaoka, Kagoshima 890-8544, Japan. ${ }^{2}$ Field of Maxillofacial Diagnostic and Surgical Science, Department of Oral and Maxillofacial Rehabilitation, Kagoshima University Graduate School of Medical and Dental Sciences, 8-35-1 Sakuragaoka, Kagoshima 890-8544, Japan.

Received: 15 December 2013 Accepted: 12 February 2014 Published: 20 February 2014

\section{References}

1. Pfaller MA, Jones RN, Doern GV, Sader HS, Hollis RJ, Messer SA: International surveillance of blood stream infections due to Candida species: frequency of occurrence and antifungal susceptibilities of isolates collected in 1997 in the United States, Canada, and south america for the SENTRY program. The SENTRY participant group. J Clin Microbiol 1997, 36:1886-1889.

2. Messer SA, Moet GJ, Kirby JT, Jones RN: Activity of contemporary antifungal agents, including the novel echinocandin anidulafungin, tested against Candida spp., Cryptococcus spp., and aspergillus spp.: report from the SENTRY antimicrobial surveillance program (2006 to 2007). J Clin Microbiol 2009, 47:1942-1946. 
3. Villanueva A, Arathoon EG, Gotuzzo E, Berman RS, DiNubile MJ, Sable CA: A randomized double-blind study of caspofungin versus amphotericin for the treatment of candidal esophagitis. Clin Infect Dis 2001, 33:1529-1535.

4. Villanueva A, Gotuzzo E, Arathoon EG, Noriega LM, Kartsonis NA, Lupinacci RJ, Smietana JM, DiNubile MJ, Sable CA: A randomized double-blind study of caspofungin versus fluconazole for the treatment of esophageal candidiasis. Am J Med 2002, 113:294-299.

5. de Wet N, Llanos-Cuentas A, Suleiman J, Baraldi E, Krantz EF, Della Negra M, Diekmann-Berndt $\mathrm{H}$ : A randomized, double blind, parallel group, doseresponse study of micafungin compared with fluconazole for the treatment of esophageal candidiasis in HIV positive patients. Clin Infect Dis 2004, 39:842-8499.

6. Krause DS, Simjee AE, van Rensburg C, Viljoen J, Walsh TJ, Goldstein BP, Aible $M$, Henkel T: A randomized, double-blind trial of anidulafungin versus fluconazole for the treatment of esophageal candidiasis. Clin Infect Dis 2004, 39:770-775

7. Takakura S, Fujihara N, Saito T, Kudo T, linuma Y, Ichiyama S, the Japan invasive mycosis surveillance study group: National surveillance of species distribution in blood isolates of Candida species in Japan and their susceptibility to six antifungal agents including voriconazole and micafungin. J Antimicrob Chemother 2004, 53:283-289.

8. Yamaguchi H, Uchida K, Okuzumi K, Oguri T, Adachi K, Kawakami S, Tosaka M, Kawashima C, Hori Y, Kitazawa T, Hayamshi M, Saito Y, Ozaki K, Nishiyama Y: Nationwide survey of antifungal drug susceptibility of clinical fungal isolates in Japan for the Japan antifungal surveillance program (JASP), 2001-2002. J Jpn Soc Clin Microbiol 2004, 14:183-193.

9. Yamaguchi H, Uchida K, Nishiyama Y, Okuizumi K, Oguri T, Adachi K, Kawakami S, Tosaka M, Misawa Y, Kawashima C, Hori Y, Kitazawa T, Hayashi M, Okimura Y: Nationwide survey of antifungal drug susceptibility of clinical fungal isolates in Japan for the Japan antifungal surveillance program (JASP), 2003. J Jpn Soc Clin Microbiol 2006, 16:13-22.

10. Yamaguchi H, Nishiyama Y, Uchida K, Takahashi C, Kawashima C, Hayashi M, Kawakami S, Adachi K, Okuizumi K, Misawa Y, Oguri T, Okimura Y, Kitazawa T, Hori Y, Tosaka M: Nationwide survey of antifungal drug susceptibility of clinical fungal isolates in Japan for the Japan antifungal surveillance program (JASP), 2005. J Jpn Soc Clin Microbiol 2009, 19:128-141.

11. Kamikawa Y, Nagayama T, Fujisaki J, Hirabayashi D, Kawasaki K, Hamada T, Mori Y, Kamikawa Y, Mukai H, Sato T, Sugihara K: Clinical study on anti-fungal drug activity against clinically isolated strains of oral Candida species. Oral Sci Int 2013, 10:87-94

12. Sudo T, Makimura K, Kawata K, Ito A, Oka S, Uchida K, Yamaguchi H: Evaluation of antifungal susceptibility testing by the broth micro dilution method against Candida species: activities of 5 antifungal agents against Candida species isolated from oral candidiasis or other candidal infectious diseases and correlation of vitro data and clinical outcome of fluconazole therapy. Jpn J Chemotherapy 1997, 45:115-122.

13. Kanbe T, Horii T, Arishima T, Ozeki M, Kikuchi A: PCR-based identification of pathogenic Candida species using primer mixes specific to Candida DNA topoisomerase II genes. Yeast 2002, 19:973-989.

14. Pappas PG, Kauffman CA, Andes D, Benjamin DK Jr, Calandra TF, Edwards JE Jr, Filler SG, Fisher JF, Kullberg BJ, Ostrosky-Zeichner L, Reboli AC, Rex JH, Walsh TJ, Sobel JD: Clinical practice guidelines for the management of candidiasis: 2009 update by the infectious diseases society of America. Clin Infect Dis 2009, 48:503-535.

15. Clinical and Laboratory Standards Institute: Reference method for broth dilution antifungal susceptibility testing of yeasts. Approved standard-third edition M27-A3. Wayne PA USA: CLSI; 2008.

16. Yamaguchi H: Anti-fungal drug sensitivity test. Modern media 2009, 55:309-320

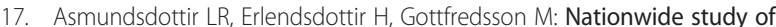
candidemia, antifungal use, and antifungal drug resistance in Iceland, 2000 to 2011. J Clin Microbiol 2013, 51:841-848.

18. de Almeida AA, Mesquita CSS, Svidzinski TIES, de Oliveira KMP: Antifungal susceptibility and distribution of Candida spp. Isolates from the university hospital in the municipality of Dourados, state of Mato Grosso do Sul, Brazil. Rev Soc Bras Med Trop 2013, 46:335-339.

19. De luca C, Guglielminetti M, Ferrario A, Calabrò M, Casari E: Candidemia: species involved, virulence factors and antimycotic susceptibility. New Microbiol 2012, 35:459-468.
20. Santhanam J, Yahaya N, Aziz MN: Species distribution and antifungal susceptibility patters of Candida species: is low susceptibility to itaconazole a trend in Malaysia? Med J Mlaysia 2013, 68:343-347.

21. Pfaller M, Neofytos D, Diekema D, Azie N, Meier-Kriesche HU, Quan SP, Horn D: Epidemiology and outcomes of candidemia in 3648 patients: data from the prospective antifungal therapy (PATH alliance ${ }^{\circledast}$ ) registry 2004-2008. Diagn Microbiol Infect Dis 2012, 74:323-331.

22. Moretti ML, Trabasso P, Lyra L, Fagnani R, Resende MR, de Oliveira Cardoso LG, Schreiber AZ: Is the incidence of candidemia caused by Candida glabrata increasing in Brazil? Five-year surveillance of Candida bloodstream infection in a university reference hospital in southeast Brazil. Med Mycol 2013, 51:225-230

23. Zhang XB, Yu SJ, Yu JX, Gong YL, Feng W, Sun FJ: Retrospective analysis of epidemiology and prognostic factors for candidemia at a hospital in China, 2000-2009. Jpn J Infect Dis 2012, 65:510-515.

24. Hoegl L, Thoma-Greber E, Röcken M, Korting HC: Persistent oral candidosis by non-albicans Candida strains including Candida glabrata in a human immunodeficiency cirus-infected patient observed over a period of 6 years. Mycoses 1998, 41:335-338.

25. Redding SW, Kirkpatrick WR, Coco BJ, Sadkowski L, Fothergill AW, Rinaldi MG, Eng TY, Patterson TF: Candida glabrata oropharyngeal candidiasis in patients receiving radiation treatment for head and neck cancer. J Clin Micribiol 2002, 40:1879-1881.

26. Trick WE, Fridkin SK, Edwards JR, Hajjeh RA, Gaynes RP: Secular trend of hospital-acquired candidemia among intensive care unit patients in the United States during 1989-1999. Clin Infect Dis 2002, 35:627-630.

27. Nguyen MH, Peacock JE, Morris AJ, Tanner DC, Nguyen ML, Snydman DR, Wagener MM, Rinaldi MG, Yu VL: The changing face of candidemia: Emergence of non-Candida albicans species and antifungal resistance. Am J Med 1996, 100:617-623.

28. Pfaller AM, Jones RN, Messer SA, Edmond MB, Wenzel RP: National surveillance of nosocomial blood stream infection due to species of Candida other than Candida albicans: Frequency of occurrence and antifungal susceptibility in the SCOPE program. Diag Microbiol Infect Dis 1998, 30:121-129.

29. Silva S, Henriques M, Hayes A, Oliveira R, Azeredo J: Candida glabrata and Candida albicans co-infection of an in vitro oral epithelium. Oral Pathol Med 2011, 40:421-427.

30. Meurman JH, Siikala E, Richardson M, Rauteman R: Non-Candia albicans Candida yeasts of the oral cavity. Communicating current research and educational topics and trends in applied microbiology. Madrid: Formatex; 2007:719-731.

31. Sanita PV, de Oliveira Mima EG, Pavarina AC, Jorge JH, Machando AL, Vergani CE: Susceptibility profile of a Brazilian yeast stock collection of Candida species isolated form subjects with Candida-associated denture stomatitis with or without diabetes. Oral Surg Oral Med Oral Pathol Oral Radiol 2013, 116:562-569.

\section{doi:10.1186/1472-6831-14-14}

Cite this article as: Kamikawa et al:: Frequency of clinically isolated strains of oral Candida species at Kagoshima University Hospital, Japan, and their susceptibility to antifungal drugs in 2006-2007 and 20122013. BMC Oral Health 2014 14:14.

\section{Submit your next manuscript to BioMed Central and take full advantage of:}

- Convenient online submission

- Thorough peer review

- No space constraints or color figure charges

- Immediate publication on acceptance

- Inclusion in PubMed, CAS, Scopus and Google Scholar

- Research which is freely available for redistribution 